\title{
Broken colinearity of the amphioxus Hox cluster
}

\author{
Juan Pascual-Anaya ${ }^{1,2}$, Noritaka Adachi ${ }^{2}$, Susana Álvarez ${ }^{3}$, Shigeru Kuratani ${ }^{2}$, Salvatore D'Aniello ${ }^{1,4^{*}}$ \\ and Jordi Garcia-Fernàndez ${ }^{1 *}$
}

\begin{abstract}
Background: In most eumetazoans studied so far, Hox genes determine the identity of structures along the main body axis. They are usually linked in genomic clusters and, in the case of the vertebrate embryo, are expressed with spatial and temporal colinearity. Outside vertebrates, temporal colinearity has been reported in the cephalochordate amphioxus (the least derived living relative of the chordate ancestor) but only for anterior and central genes, namely Hox 1 to Hox4 and Hox6. However, most of the Hox gene expression patterns in amphioxus have not been reported. To gain global insights into the evolution of Hox clusters in chordates, we investigated a more extended expression profile of amphioxus Hox genes.
\end{abstract}

Results: Here we report an extended expression profile of the European amphioxus Branchiostoma lanceolatum Hox genes and describe that all Hox genes, except Hox13, are expressed during development. Interestingly, we report the breaking of both spatial and temporal colinearity for at least Hox6 and Hox 14 , which thus have escaped from the classical Hox code concept. We show a previously unidentified Hox6 expression pattern and a faint expression for posterior Hox genes in structures such as the posterior mesoderm, notochord, and hindgut. Unexpectedly, we found that amphioxus Hox 14 had the most divergent expression pattern. This gene is expressed in the anterior cerebral vesicle and pharyngeal endoderm. Amphioxus Hox 14 expression represents the first report of Hox gene expression in the most anterior part of the central nervous system. Nevertheless, despite these divergent expression patterns, amphioxus Hox6 and Hox 14 seem to be still regulated by retinoic acid.

Conclusions: Escape from colinearity by Hox genes is not unusual in either vertebrates or amphioxus and we suggest that those genes escaping from it are probably associated with the patterning of lineage-specific morphological traits, requiring the loss of those developmental constraints that kept them colinear.

Keywords: Hox gene regulation, Hox cluster evolution, Amphioxus, Hox colinearity, Retinoic acid

\section{Background}

Hox genes code for a subfamily of homeodomaincontaining transcription factors and have been found in all eumetazoans studied so far. Hox genes are responsible for giving the identity to morphological structures along the anterior-posterior (A-P) axis in most bilaterian animals [1-4]. Generally, these genes lie in the same genomic region and form gene clusters, usually one in invertebrates, and multiple clusters in vertebrates because of multiple rounds of genome duplication that took place at their origin (Figure 1) [5,6]. In most groups

\footnotetext{
* Correspondence: salvatore.daniello@szn.it; jordigarcia@ub.edu

'Departament de Genètica and Institut de Biomedicina (IBUB), University of Barcelona, Av. Diagonal, 643, Barcelona 08028, Spain

${ }^{4}$ Cellular and Developmental Biology, Stazione Zoologica Anton Dohrn, Villa Comunale, Naples 80121, Italy

Full list of author information is available at the end of the article
}

of animals, the position of Hox genes within any cluster corresponds with their mode of expression: genes placed more toward the $3^{\prime}$ end are expressed and pattern more anterior structures than do genes placed at the $5^{\prime}$ end. As a result, Hox genes are expressed along the A-P axis in a nested manner with more rostral limits for $3^{\prime}$ than for $5^{\prime}$ genes. This phenomenon is called spatial colinearity [7]. Moreover, in the case of vertebrates, the $3^{\prime}$ genes are expressed in earlier stages of the developing embryo than are $5^{\prime}$ genes in what is known as temporal colinearity [8,9]. The different combinations of Hox genes expressed in different structures along the A-P axis constitute what is called the Hox code [10]. It is believed that changes in the patterns of Hox expression are somehow responsible for the appearance of some vertebrate innovations, such as the elaboration of the segmentation of the hindbrain [11].

\section{Biomed Central}


Chordates include the group olfactores (vertebrates and urochordates) and the cephalochordates [12] (Figure 1). However, urochordates, as a reflection of their highly reorganized genome and extensive gene losses, do not retain the typical clustered organization of Hox genes with only some genes linked, as in the ascidian Ciona intestinalis $[13,14]$ (Figure 1), or as an atomized cluster, as is the case of the larvacean Oikopleura dioica [15] (Figure 1). Nonetheless, the cephalochordate amphioxus, representing the most basal branch of chordates, has a rather prototypical genome [16] and possesses a single cluster of 15 Hox genes, where all of them are transcribed in the same orientation, as in vertebrates [17]. Thus, amphioxus represents the best model to compare with vertebrates for illuminating the basal condition of chordates for both Hox content and regulation. However, the expression of amphioxus Hox genes is scarcely reported and studies have focused mainly on the anterior ones. The genes of the Floridian amphioxus Branchiostoma floridae Hox1-4 and Hox6 have been reported to be expressed during development in a colinear manner in the central nervous system (CNS), highlighting that, although it is not morphologically segmented as in vertebrates, the CNS in both groups to some extent conserves the same nested Hox system [18]. In addition, the expression patterns of Hox1, Hox 3 , and Hox4 have been reported in the epidermis and have been associated with the determination of different sensory neurons along the A-P axis [19]. Moreover, Hox 1 mRNA is expressed in the middle part of the gut [20].

The acidic form of vitamin A, retinoic acid (RA), has an important role in the regionalization of morphological structures along the A-P axis of vertebrates, acting as the main posteriorizing factor during neural determination [21]. Its function is carried out in a gradient-dependent manner, with higher concentrations in posterior parts [22]. In the case of amphioxus, an excess of RA during development also causes changes of anterior into posterior identities, and the mouth and gill

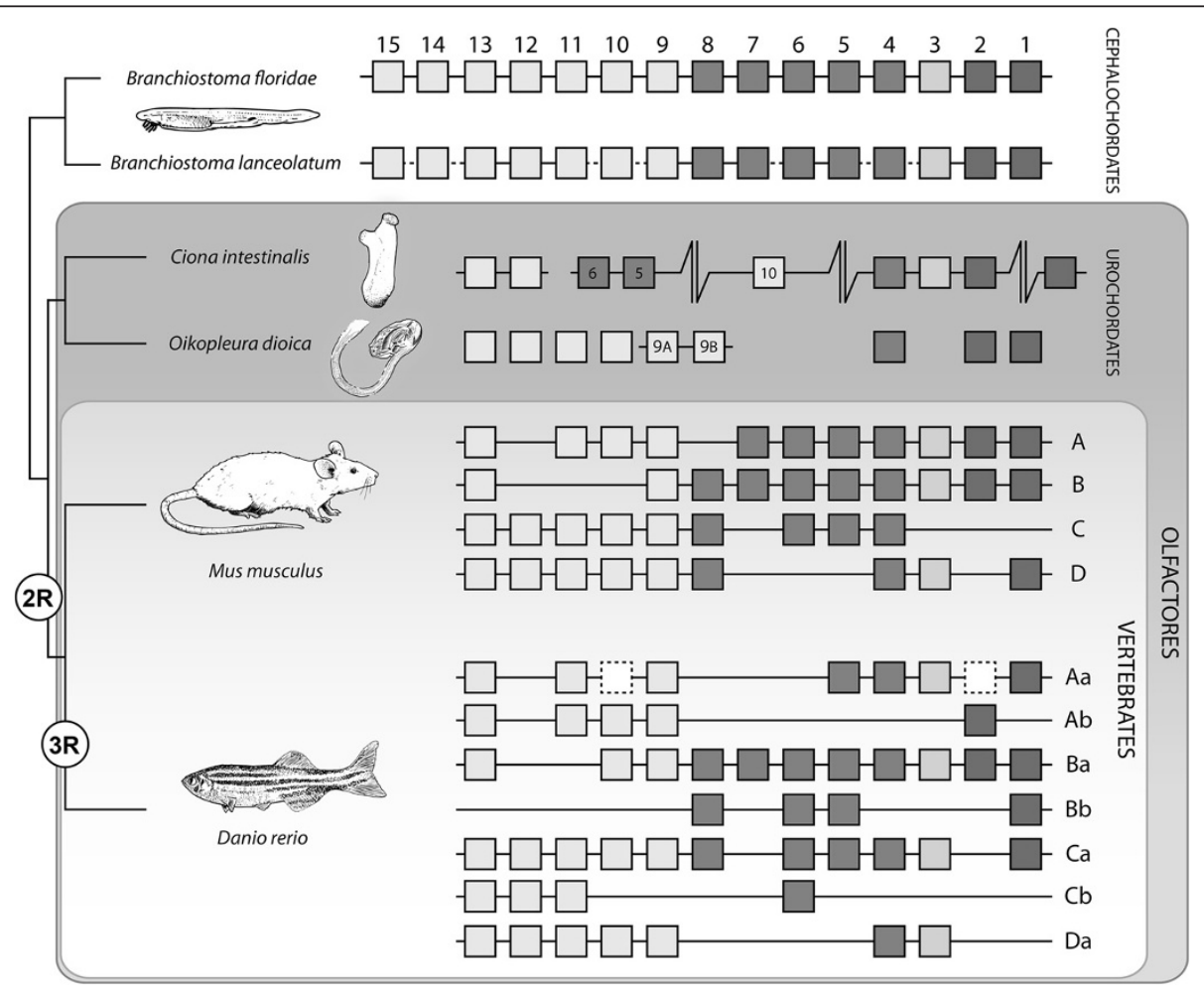

Figure 1 Phylogenetic positions of cephalochordates, urochordates, and vertebrates, showing their Hox contents. The cephalochordate amphioxus represents the basal branch of chordates and possesses a single Hox cluster of 15 genes in both B. floridae and B. lanceolatum, although the whole genomic sequence of the latter has not been reported yet (indicated by dashed lines in the corresponding regions). Urochordates, the sister group of vertebrates, possess a disintegrated Hox cluster at different levels. Whereas the ascidian Ciona intestinalis has a highly disintegrated cluster with several reorganizations, the larvacean Oikopleura dioica has a completely atomized cluster where only two Hox 9 genes remain linked, probably arising from an independent duplication. Vertebrates have multiple clusters, such as four in the mouse caused by two rounds of genome duplication (2R), or the seven clusters of zebrafish after a third teleost-specific round of genome duplication (3R). Squares represent Hox genes, with the same gray-scale colors indicating different paralogous groups (PG1 and PG2, PG3, central PG4-8, and posterior PG9-13/15). White boxes with dashed outlines represent pseudogenes. 
slits do not form. Conversely, treatments with RA antagonists result in a caudal extension of the pharynx $[23,24]$. These effects caused by altered concentrations of RA during development are equivalent to those observed in vertebrate embryos and highlight that determination mechanisms of the structures along the A-P axis are somehow conserved in chordates. RA carries out its function by binding heterodimers of the RA receptor (RAR) and retinoid $\mathrm{X}$ receptor (RXR), which regulate the transcription of their target genes by binding to RA response elements (RAREs) in the regulatory regions of the genome. RAREs consist of two direct repeats (DRs) separated by a variable number of nucleotides. In the case of RAR/RXR heterodimers, they have been shown to bind DRs separated by one (DR1), two (DR2), or five (DR5) nucleotides [25]. RA has an important role in controlling Hox genes [26,27] via RAR/RXR binding to RAREs [28-30]. Besides, the anterior Hox genes in amphioxus are regulated by RA [18-20], and morpholino knock-down of Hox 1 produces the same phenotype as treatment with an RA antagonist, indicating that Hox 1 mediates the function of RA to establish the posterior limit of the pharynx [20]. Therefore, the regulation of anterior Hox genes by RA seems to be conserved between vertebrates and amphioxus, as suggested by heterologous reporter assays using regulatory regions of amphioxus Hox genes in both the mouse and chicken $[31,32]$. Again, most of these studies were focused on the anterior part of the cluster; hence, a general scenario for Hox cluster regulatory evolution is not yet available.

In this study, we report previously undescribed expression patterns of Hox genes of the European amphioxus Branchiostoma lanceolatum, and, surprisingly, find that some of them are not expressed in a colinear manner either in space or time, thus breaking the paradigm of Hox colinearity in amphioxus. We identified a different expression for B. lanceolatum Hox6 than that previously reported for the Floridian amphioxus [18,33] and detected Hox 14 expression in the pharyngeal endoderm at the level of the endostyle, the mid-hindgut, and notochord. Strikingly, it was detected in the cerebral vesicle, a part of the CNS where no Hox expression has been detected so far. Thus, this gene has escaped from the Hox coding pattern, as has been reported for vertebrate Hox 14 genes [34,35]. We then investigated the regulation of these genes by RA and found that RA regulated the expression of Hox 6 and the expressions of Hox 14 in the gut and notochord. It also affected Hox14 expression in the cerebral vesicle, whereas the regulation of Hox 14 in the pharyngeal endoderm seemed to be RA independent. The presence of RAREs near these genes, conserved between both the Floridian and European amphioxus species, makes these genes colinearity-breakers but still likely targets of RA regulation.

\section{Methods}

\section{Embryonic culture and treatment with RA and the RA} antagonist BMSO09

Sexually mature amphioxus adults (B. lanceolatum) were collected in Argelés-sur-Mer (France) during the summer of 2009. Spawning was induced in the laboratory by heat shock [36]. After fertilization, embryos were reared in filtered seawater at $17^{\circ} \mathrm{C}$. Treatments with RA (in DMSO), the RA antagonist BMS009 (in DMSO), or equivalent amounts of DMSO (as control) were carried out at the late blastula stage at a final concentration of $1 \times 10^{-6} \mathrm{M}$ as described [23,24]. At the early neurula stage, embryos were transferred to untreated filtered seawater, washed a few times, and kept in normal conditions. The control DMSO treatment did not affect development. Embryos and larvae were fixed at frequent intervals with $4 \%$ paraformaldehyde overnight at $4{ }^{\circ} \mathrm{C}$ in a buffer containing $0.1 \mathrm{M}$ MOPS, $0.5 \mathrm{M} \mathrm{NaCl}, 2 \mathrm{mM}$ $\mathrm{MgSO}_{4}, 1$ mM EGTA, pH 7.4 for in situ hybridization.

\section{Extension of the genomic region of $B$. lanceolatum Hox 11}

Because the coding sequences of $B$. floridae and $B$. lanceolatum are extremely conserved, we decided to use primers based on the B. floridae Hox11 exon 2 to amplify the first intron of $B$. lanceolatum's one. Using a forward primer from the B. lanceolatum Hox 11 exon 1 (5'-ATGGACGGTTACTGGCTGC-3', [37]) and a reverse primer designed on the B. floridae Hox 11 exon 2 sequence (5'-CTGCCTATCCGTGAGGTTG-3', [38]), we amplified a band of approximately $2.5 \mathrm{Kbp}$ using $B$. lanceolatum genomic DNA as a template. We cloned it into pGEM-T Easy Vector (Promega) and sequenced it. The sequence corresponded to the first exon, first intron, and second exon of B. lanceolatum Hox 11. The genomic sequence with the new annotation has been uploaded to the NCBI GenBank Database (http://www.ncbi.nlm.nih.gov/ genbank/) under accession no. JX508623.

\section{cDNA cloning, whole-mount in situ hybridization (WISH),} microscopy, and photography

A mix of embryo stages from gastrula to 2-day-old larvae of B. lanceolatum were fixed in RNAlater (Ambion) and total RNA was extracted using RNeasy Mini Kit (QIAGEN). The cDNA first strand was synthesized using Superscript III Reverse Transcriptase (Invitrogen) $\left(1 \mathrm{~h}, 56^{\circ} \mathrm{C}\right)$. An embryo cDNA library was constructed using the CloneMiner Kit (pDNR222 vector; Invitrogen). Reverse transcription polymerase chain reaction (RTPCR) amplification of the coding DNA sequence (CDS) and $5^{\prime}$ - or $3^{\prime}$-rapid amplification of cDNA ends (RACE; Invitrogen) for all B. lanceolatum Hox genes (Hox 1-15) were carried out with primers designed based on the sequences reported previously [37], except for Hox11, where we used the sequence of the exon 2 described 
here. We did not obtain any positive result for Hox 13 and could not amplify the $3^{\prime}$-untranslated regions (UTRs) for Hox9, Hox11, and Hox15. For Hox11 we obtained the 5'-UTR. For Hox1, Hox3, Hox4, Hox6, Hox7, and Hox10 we obtained the 3'-UTR sequences. For Hox 14 we obtained both $5^{\prime}$ - and $3^{\prime}$-UTRs. For Hox9 we had only the $5^{\prime}$-UTR. We also searched for Hox 13 in the recently published embryonic transcriptome of $B$. lanceolatum [39] but did not find any entry. Based on the sequences of the $3^{\prime}$-RACE clones, primers were designed to clone part of the $3^{\prime}$-UTR. CDS or $3^{\prime}$-UTR of each Hox gene was cloned into pBluescript SKII+, pCRII-TOPO Dual Promoter vector (Invitrogen), or pGEM-T Easy Vector (Promega), sequenced on both strands and used as templates for ribosynthesis of antisense digoxigenin-labelled probes. All primers used in this study are listed in Additional file 1: Table S1, and the region of the gene used in every case is depicted in Figure 2B. WISH was performed as described [40]. For Hox3, Hox4, Hox6, Hox7, Hox10, and Hox 14, only the probes based in the 3 '-UTR worked in the WISH procedures. None of the probes used gave signals for Hox2, Hox5, Hox8, Hox9, Hox11, Hox12, or Hox15. For Hox1, the riboprobe used was based on the whole CDS of the gene and the $3^{\prime}$-UTR, with both giving the same signal. Sequences of clones used in this study were uploaded to the NCBI GenBank Database under accession numbers JX088059-JX088072 and JX508612-JX508622. After WISH, the embryos were photographed as whole mounts. Several focus planes were merged using Helicon Focus software (d-Studio) for a more accurate identification of expression territories.

\section{Identification of RAREs}

Sequences of lambda phages containing either $B$. lanceolatum Hox6 and Hox5 (lambda phage no. $\lambda 4131$ $+\lambda 4184$ described in [37]) or Hox14 (lambda phage no. $\lambda 4100$ in [37]) and their equivalent sequences from $B$. floridae [38] were analyzed by nuclear hormone receptor (NHR) scan using default parameter values [41]. We compared the results for sequences in both species and only those elements conserved in both $B$. floridae and $B$. lanceolatum were considered.

\section{Results}

B. lanceolatum Hox1, Hox3, and Hox4 expression patterns: genes that follow colinearity

The only amphioxus Hox genes for which the expression has been reported so far are Hox 1 to Hox4 and Hox6 of the Floridian species $B$. floridae [18,42]. We used the sibling species $B$. lanceolatum to investigate the hitherto unknown expression of several Hox genes by WISH. As

A

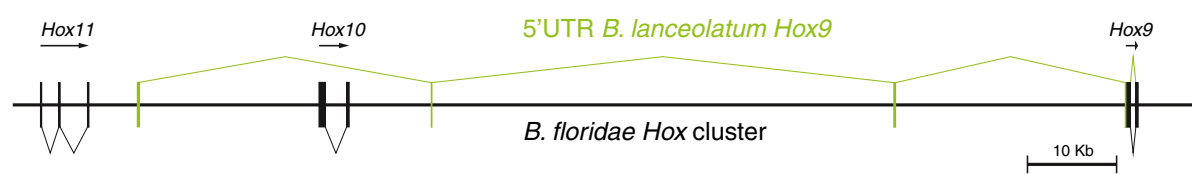

B

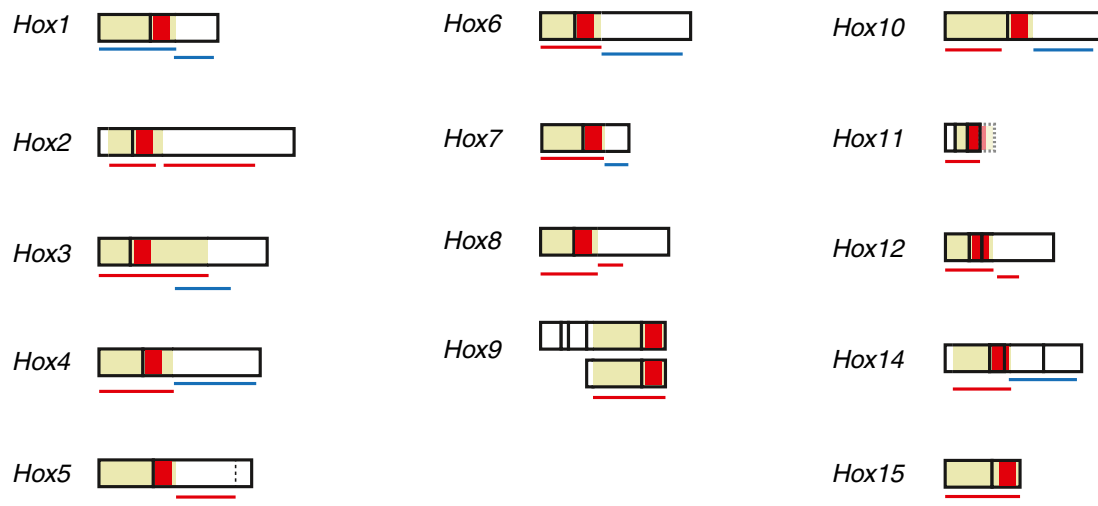

Figure 2 5'-UTR of B. lanceolatum Hox9 and probes used in this study. (A) Scheme of the B. floridae Hox cluster with Hox 11, Hox 10, and Hox9 represented. The $B$. lanceolatum Hox9 transcripts consist of two different versions: a large one, with three $5^{\prime}$-UTR (in green) exons far upstream of the Hox9 locus, with its splicing shown at the top. A shorter one, with a canonical $5^{\prime}$-UTR next to the first exon of Hox9, is shown with its splicing represented at the bottom. Black vertical lines represent exons of the different Hox genes. (B) The transcripts of all the B. lanceolatum Hox genes found to be expressed in this study. Color-coded boxes represent exons: beige, coding sequences; white, UTRs; and red, homeoboxes. The lines under the transcripts represent the probes used: red, a negative probe; blue, a positive probe. The third exon of B. lanceolatum Hox 11 has not yet been described, so it is represented with a dashed line and fainter colors. 
expected [43], we found that the expression patterns of B. lanceolatum Hox 1, Hox3, and Hox4 in the CNS and mesoderm were very similar to those of their orthologous genes in B. floridae [18,42], in a clear colinear manner (Figure 3). However, while Schubert et al. [19] described a Hox nested expression of Hox1, Hox3, and Hox4 in scattered epidermal cells (likely involved in the patterning of developing sensory neurons) we found subtle differences in B. lanceolatum. The epidermal domain of B. lanceolatum Hox 1 consisted of scattered cells in a mid-domain of the embryo, as described by Schubert et al. [19] (Figure 3, black arrows in Hox1). The most anterior limit of B. lanceolatum Hox 1 in the CNS coincides with the most anterior limit in the epidermis (Figure 3). This epidermal expression of Hox 1 is also clear from a dorsal point of view (see Additional file 2: Figure S1). However, in the case of Hox3, the high level of background obscured this pattern, although from a dorsal viewpoint there appeared to be epidermal expression at the late neurula stage (Additional file 2: Figure S1) as in B. floridae. Surprisingly, we were not able to detect epidermal expression of Hox4 (Figure 3), which was expressed only in the CNS.

\section{A different expression pattern found for amphioxus Hox6} in the CNS: breaking spatial and temporal colinearity

Two different expression patterns have been reported so far for B. floridae Hox6. The first report described Hox6 as being expressed in all the neural tube posterior to the cerebral vesicle and in the endoderm up to the first gill slit, thereby breaking colinearity [33]. The second report showed a canonical expression in the CNS following colinearity with Hox 1-4 [18]. To clarify this disparity, we studied the expression of B. lanceolatum Hox6. Surprisingly, we found a different pattern from those reported above. Unlike Hox1, Hox3, and Hox4, B. lanceolatum Hox6 was expressed in a restricted part of the neural plate at the mid-neurula stage, with very sharp anterior and posterior limits (Figure 4A'). The anterior limit was at the level of the intersomitic cleft between somites 5 and 6 and the posterior limit was two somites behind (Figure 4A'), unlike B. floridae Hox6, which Schubert et al. described to be expressed from the level between somites 6 and 7 (one somite behind the European amphioxus $H o x 6$ ) rearwards to the tail bud [18]. It is remarkable that B. lanceolatum Hox6 was not expressed in the posterior CNS and tail bud. The anterior limit of Hox4 in amphioxus is at the level of the middle point of somite 6 , half a somite behind Hox6, which means that Hox6 breaks spatial colinearity slightly. Regarding the timing, we have detected Hox6 exclusively at the midneurula stage (between $18 \mathrm{~h}$ and $21 \mathrm{~h}$ of development at $17^{\circ} \mathrm{C}$ ), earlier than Hox4 expression (which is expressed from $24 \mathrm{~h}$ onwards, from late neurula stage), thus breaking temporal colinearity. B. lanceolatum Hox6 was not detected any later in development. The role of Hox6 must be very specific both in time and space in patterning of the CNS.

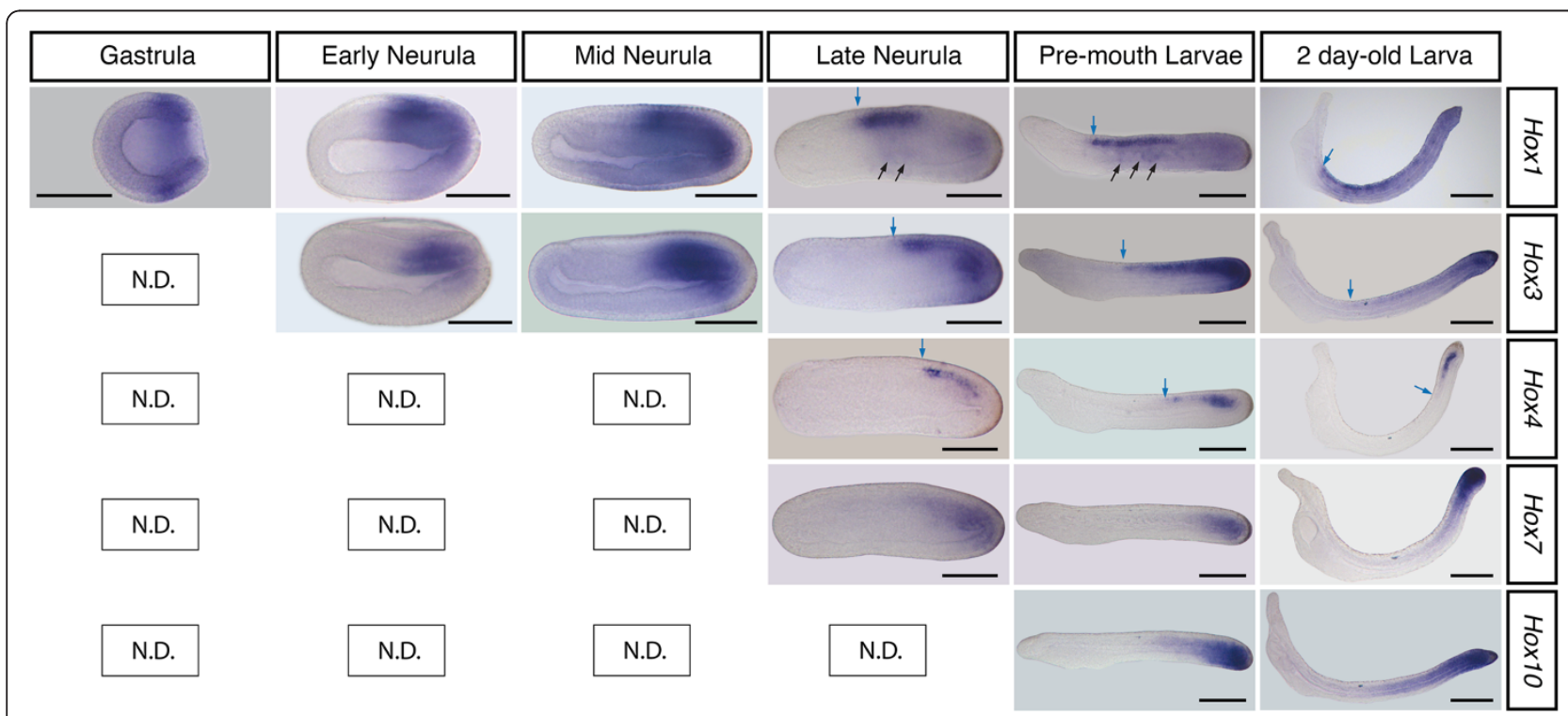

Figure 3 B. lanceolatum Hox gene expression patterns. Expression profile of anterior (Hox 1 and Hox3), central (Hox4 and Hox7), and posterior (Hox10) genes of the B. lanceolatum Hox cluster are shown in lateral views of amphioxus embryos from the gastrula stage (left-most panel) to the larval stage (48 h post fertilization, right panels). Whereas Hox 1 was expressed in scattered cells in the epidermis (arrows in the Hox 1 panels of the late neurula and pre-mouth larval stage), this was not clear for Hox3 and was definitely absent for Hox4. Blue arrows indicate the anterior limit of expression in the CNS. In all panels, dorsal is on the top and anterior is to the left. ND, non-detected signal. Scale bars $=100 \mu \mathrm{m}$. 

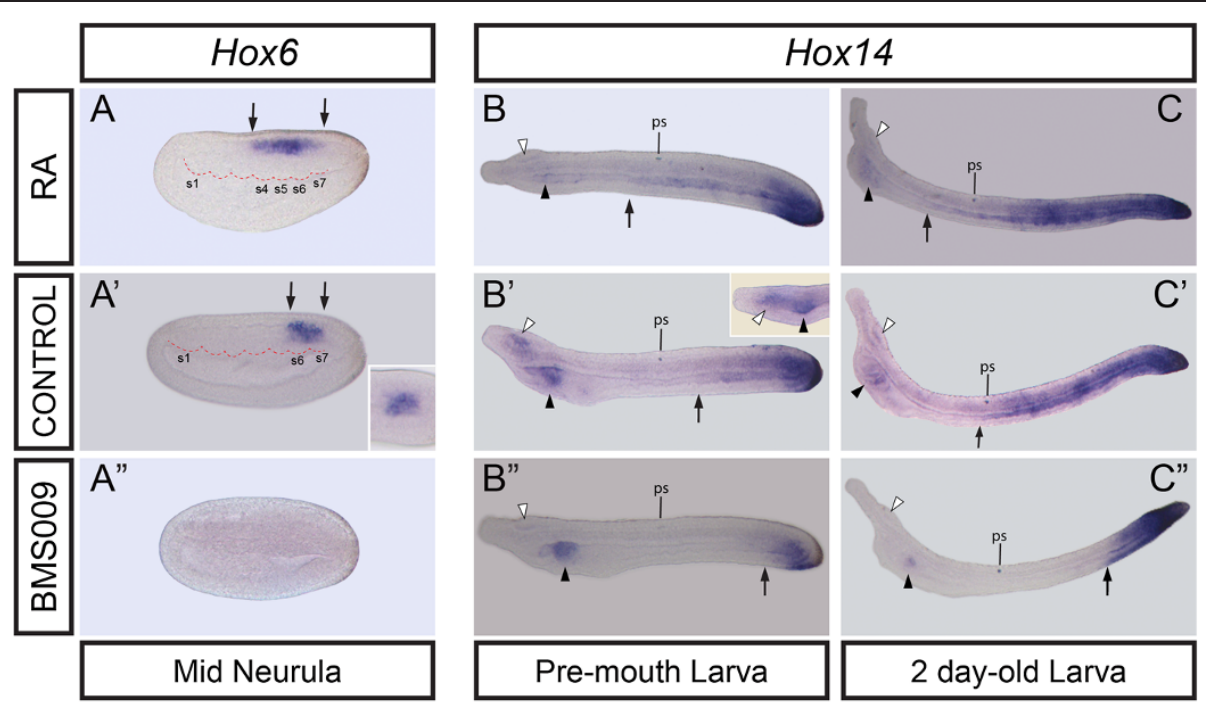

D
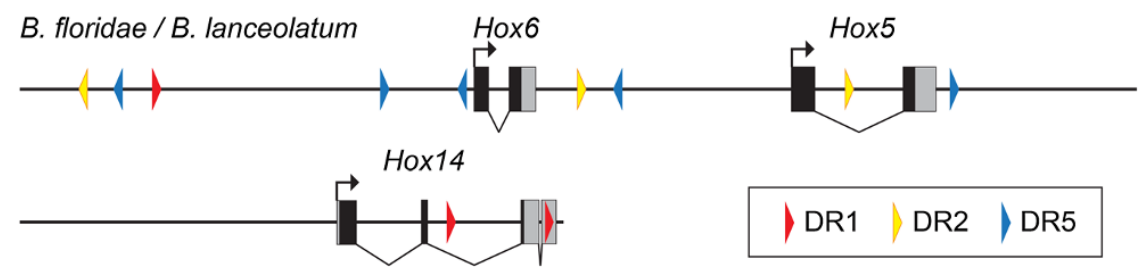

Figure 4 Retinoic acid (RA) regulation of Hox6 and Hox14. Expression patterns of B. lanceolatum Hox6 and Hox14 and their alterations in embryos treated with RA (upper panels) or the RA antagonist BMS009 (lower panels). (A') Hox6 was expressed only in a very specific region of the neural plate at the mid-neurula stage and not in the mesoderm (dorsal view in inset). Its anterior limit was enlarged rostrally in RA-treated embryos (A) compared with controls $\left(\mathbf{A}^{\prime}\right)$; the posterior limit remained fixed (limits marked by black arrows). The Hox6 domain disappeared in BMS009-treated embryos $\left(\mathbf{A}^{\prime \prime}\right)$. ( $\left.\mathbf{B}^{\prime}, \mathbf{C}^{\prime}\right)$ Hox14 was expressed in the posterior half of the notochord and gut, with a diffuse anterior limit (black arrow), in the cerebral vesicle (white arrowhead) and the left side of the pharyngeal endoderm (black arrowhead). A dorsal view of the head region (inset of $\mathbf{B}^{\prime}$ ), shows expression in the left part of the pharyngeal endoderm. (B, C) In RA-treated embryos, Hox 14 expression in the notochord and gut has extended rostrally in both pre-mouth stage and 2-day-old larvae compared with DMSO-treated embryos ( $\left.\mathbf{B}^{\prime}, \mathbf{C}^{\prime}\right)$, taking the pigment spot (ps) as a reference point. In embryos treated with BMS009, the anterior border of expression was caudally shifted strongly in notochordal and gut domains $\left(\mathbf{B}^{\prime \prime}, \mathbf{C}^{\prime \prime}\right)$. Expression in the cerebral vesicle was strongly reduced by RA or RA antagonist treatments (B and $\mathbf{C}_{;} \mathbf{B}^{\prime \prime}$ and $\mathbf{C}^{\prime \prime}$ ). The pharyngeal domain remained after both treatments $\left(\mathbf{B}, \mathbf{C}\right.$ and $\left.\mathbf{B}^{\prime \prime}, \mathbf{C}^{\prime \prime}\right)$, even though the severe phenotype in the case of the RA-treated pre-mouth larva showed strongly reduced expression in the pharynx (B). (D) Schemes of the genomic regions surrounding the loci of Hox6 and Hox5 (top), and Hox14 (bottom) depicting the RAREs of types DR1 (red), DR2 (yellow), and DR5 (blue) that are conserved in both B. floridae and B. lanceolatum [37].

\section{European amphioxus $\operatorname{Hox} 7$ and Hox10 expression patterns}

Apart from Hox4 and Hox6, no other Hox gene expressions have been reported for the central group in cephalochordates. We detected a very weak expression of Hox7 in the CNS, mesoderm, and tail bud (Figure 3). Due to its weak expression, we cannot rule out the possibility that B. lanceolatum Hox7 was expressed in other tissues. At the late neurula stage, the anterior limit of Hox 7 was at a level equivalent to that of Hox4, but the anterior expression was so blurred that establishing a clear boundary was difficult; thus, we could not assess the colinearity relationship between Hox4 and Hox7 at this stage. However, from the pre-mouth stage the expression is more posteriorly restricted than for Hox4. On the other hand, it began to be expressed after more anterior Hox genes, from the late neurula stage, thus retaining temporal colinearity.

No expression of Hox genes from posterior groups has been characterized in cephalochordates so far. Here we investigated the expression patterns of $B$. lanceolatum Hox10 and Hox14. We found that Hox10 expression followed a similar pattern to that for Hox7, with very weak expression in the CNS and mesoderm (Figure 3). Again, the weak and blurred expression of Hox10 makes difficult to exclude the possibility that is actually expressed in other tissues. As for Hox4 and Hox7, the anterior limit of expression of Hox10 was very diffuse, and although it seemed to be more rostral than the expressions of Hox4 and Hox7, and thus breaking spatial colinearity, the diffuse anterior limit found makes evaluating the colinearity difficult. 


\section{Non-canonical expression of Hox 14}

The most unexpected expression pattern was that of Hox 14. B. lanceolatum Hox14 is expressed from the premouth larval stage. As for most abovementioned genes, a probe for the coding sequence produced high background and unspecific signals, so we decided again to clone the 3 -UTR. We found that it was split into two exons, with a small intron of 45 bp. Amphioxus Hox14 was expressed in the mid-hindgut, in the posterior part of the notochord, and in the tail bud (Figure $4 \mathrm{~B}^{\prime}, \mathrm{C}^{\prime}$ ). Strikingly, Hox14 was also detected in anterior structures such as the cerebral vesicle and the left side of the pharyngeal endoderm at the level of the endostyle (Figure $4 \mathrm{~B}^{\prime}$ and inset).

\section{Expression of $\operatorname{Hox} 2, \operatorname{Hox} 5, \operatorname{Hox} 8, \operatorname{Hox} 9, \operatorname{Hox} 11, \operatorname{Hox} 12$, and Hox 15 detected by RT-PCR}

Apart from the genes whose expression patterns we have been able to identify, other Hox genes were detected by means of RT-PCR during $B$. lanceolatum development. Among these genes are B. lanceolatum Hox2, Hox5, Hox8, Hox9, Hox11, Hox12, and Hox15. Hox13 was not identified either by RT-PCR or in the recently published embryonic transcriptome of $B$. lanceolatum [39]. We obtained the CDSs for B. lanceolatum $\operatorname{Hox} 2, \operatorname{Hox} 5, \operatorname{Hox} 8, \operatorname{Hox} 9, \operatorname{Hox} 11$ (first and second exons but not the third), Hox 12 , and the recently discovered Hox 15 [17,37], and 3 '-UTRs by using $3^{\prime}$-RACE RTPCR for B. lanceolatum Hox2, Hox5, Hox8, and Hox 12 . We also amplified the $5^{\prime}$-UTR by means of '-RACE RTPCR of Hox2, Hox9, and Hox 11. Nonetheless, we were not able to obtain any signal by WISH (Figure 2B).

The case of amphioxus Hox2 is quite similar to that of Hox6. So far, two reports about its expression have shown two different expression patterns. The first one [42] reported the breaking of colinearity for $\operatorname{Hox} 2$, while the second [18] reported a colinear expression with respect to Hox 1 and Hox3. As with Hox6, we wanted to test which Hox2 expression pattern could be the correct one using B. lanceolatum. However, although we performed WISH with different probes based on the sequences of the CDS or the $3^{\prime}$-UTR, we were not able to obtain specific signals (Figure $2 \mathrm{~B}$ ).

We found that the $5^{\prime}$-UTR of Hox 9 had two different versions. One was shorter, with a canonical $5^{\prime}$-UTR next to the start codon, and a second larger one was divided into four exons when aligned against the B. floridae Hox cluster (the complete sequence of the B. lanceolatum Hox cluster is still not available): three of them were far upstream from Hox9. The first exon was placed approximately $5.4 \mathrm{Kbp}$ downstream of Hox 11, the second was approximately $9 \mathrm{Kbp}$ downstream of Hox 10 , and the third was approximately $25 \mathrm{Kbp}$ upstream of Hox9. The fourth corresponded to the canonical $5^{\prime}$-UTR (Figure 2A).
For B. lanceolatum Hox11, only the first exon has been annotated [37]. Here, we have extended the previously described genomic sequence up to exon 2 (see Methods), which allowed us to find Hox 11 by $5^{\prime}$-RACE RTPCR. The 5'-UTR was shorter than expected, which means that the previously automatically annotated exon $1[37,38]$ was not correct and the actual exon 1 is shorter. As with the other Hox genes, a probe based on the coding sequences of exons 1 and 2 gave no signal in WISH (Figure 2B).

\section{RA and RA-antagonist treatments alter the expression of amphioxus Hox6 and Hox 14}

The RA-Hox system controls the patterning along the A-P axis during development of chordates (for a review see [1]), and such control has been reported widely for anterior Hox genes in amphioxus [18-20,23,24,44]. Because we detected a different expression pattern for the B. lanceolatum Hox6 gene than that reported previously [18] and given that amphioxus Hox14 has been shown to have a non-canonical expression pattern, we treated embryos with RA, the RA antagonist BMS009, or with DMSO as an inert negative control, and carried out WISH experiments.

In RA-treated embryos, the anterior limit of Hox6 moved rostrally up to the level between somites 3 and 4 (compare Figure 4A with Figure 4A'), whereas the posterior limit was unaltered. When treated with the antagonist, Hox6 expression disappeared. This can be explained by the anterior limit shifting posteriorly to the extreme of its fixed posterior extent, thus making Hox6 expression disappear (compare Figure $4 \mathrm{~A}^{\prime}$ with Figure $4 \mathrm{~A}^{\prime \prime}$ ). Then, the level of the anterior limit would be that changed when taking the somites as a reference point, as in other more anterior Hox genes [18] demonstrating that the changes in expression were regulated by RA (directly or indirectly) and not because of a general shift of internal structures.

In RA-treated larvae, the anterior limit of B. lanceolatum Hox14 expression (at least in the gut) was shifted anteriorly in a significant manner compared with the control, taking as a reference point the mid pigment spot of the CNS. However, it was not so clear for the expression in the notochord (in Figure 4, compare $\mathrm{B}^{\prime}$ and $\mathrm{C}^{\prime}$ with $\mathrm{B}$ and $\mathrm{C}$, respectively). In contrast, when treated with BMS009 the expression of Hox14 in both the notochord and the gut shifted strongly to the posterior (in Figure 4, compare $\mathrm{B}^{\prime}$ and $\mathrm{C}^{\prime}$ with $\mathrm{B}^{\prime \prime}$ and $\mathrm{C}^{\prime \prime}$, respecively). Surprisingly, expression of Hox14 in the pharyngeal endoderm did not disappear completely in either RA- or BMS009-treated embryos (black arrowheads in Figure 4). Although formation of the pharynx is strongly reduced in RA-treated larvae, with mouth and gill slits failing to form [23], we detected faint expression in the pharynx of Hox 14 in the pre-mouth-stage larvae (Figure 4B, black 
arrowhead), while Hox14 was detected clearly in the case of the 2-day-old RA-treated larvae (Figure 4C, black arrowhead). This suggests that regulation of Hox14 expression in the endostyle is RA independent. The amphioxus cerebral vesicle is a structure that is also reduced in RA-treated larvae but does not disappear, as has been shown using cerebral vesicle markers [18]. Interestingly, the expression of Hox14 in the cerebral vesicle was extremely reduced with both RA and BMS009 treatments (Figures $4 \mathrm{~B}, 4 \mathrm{~B}^{\prime \prime}, 4 \mathrm{C}$ and $4 \mathrm{C}^{\prime \prime}$, white arrowheads), suggesting that the cerebral vesicle expression domain is somehow very sensitive to variations in RA level.

RA regulates the expression of its target genes via heterodimers of RAR/RXR that bind RAREs. These heterodimers can bind DR1-, DR2-, and DR5-type RAREs [25]. Using an NHR scan [41], which has been shown to be effective in the prediction of DR2 and DR5 surrounding amphioxus ParaHox genes [45], we looked for RAREs near to amphioxus Hox6 and Hox14 genes, using the same genomic regions analyzed previously for nonconserved regions [37] (see Methods). We also screened the corresponding $B$. floridae genomic sequences used in our previous comparative regulatory analysis [37], to exclude predictions that have not been conserved between both amphioxus species, because they are probably not real and functional elements. We found that most of the predicted RAREs were not conserved between both species (see Additional file 1: Tables S2 to S5). Thus, we regarded these as false-positives and they were discarded. Using these criteria, we detected one DR2 and three DR5 elements near to Hox6, and two DR1 elements within the Hox14 locus: one within the second intron and the other located in the second exon of the $3^{\prime}$-UTR (Figure 4D).

\section{Discussion}

\section{Different expression patterns between $B$. floridae}

\section{and $B$. lanceolatum}

The expression patterns of Hox 1 , Hox 3 , and Hox4 in amphioxus epidermal neurons have been reported for $B$. floridae. However, we did not detect Hox4 expression in B. lanceolatum epidermis [19]. Therefore, our data are not consistent with the hypothesis of a 'skin brain' (similar to the diffuse net of neurons in hemichordates) in amphioxus $[19,46]$.

As for Hox6, unlike the two patterns described previously in the Floridian amphioxus, we have found $B$. lanceolatum Hox6 only at the mid-neurula stage in a restricted stretch of the neural plate (Figure $4 A^{\prime}$ ). The anterior limit of $B$. lanceolatum Hox6 is one somite level more rostral than that described for B. floridae by Schubert and colleagues (between somites 7 and 8, [18]) and much more caudal than the anterior limit found by Cohn [33].
One question arises from past and current data: what can explain such different expression patterns in three different experiments? One possibility is that one of the expression patterns of $B$. floridae (in the case of Hox6, most likely that reported by Schubert et al. [18] rather than that by Cohn [33], because the signal presented by the former seems more reliable than the faint one of the latter report) and those ones presented here for B. lanceolatum actually reflect a real species-specific difference. If so, it means that the expression of B. floridae Hox 6 in the CNS in a colinear manner with the other Hox genes is not conserved in $B$. lanceolatum CNS patterning. On the other hand, it is possible that experimental consideration such as probe design may explain the differences. For example, since the nucleotide sequences of the homeobox regions of all central Hox genes are highly similar (see Additional file 2: Figure S2), a probe spanning this sequence might cause crosshybridizations and thus partial miss-assignments of expression patterns. In fact, when we used a probe based in the CDS for most of the genes, we obtained either no signal or unspecific staining of the B. lanceolatum embryos (red lines in Figure 2B). Therefore, we decided to use $3^{\prime}$ UTR-based probes, which are unable to cross-hybridize with other Hox genes. The $3^{\prime}$-RACE RT-PCR using gene specific primers designed in the first exon gave only a single band in both Hox4 and Hox6 (see Additional file 2: Figure S3), indicating that alternative splicing does not lie behind the difference and that we were detecting only the expression of Hox4 and Hox6 transcripts. However, we cannot conclusively discard the presence of alternative transcripts that could account for the different expression patterns obtained upon the use of different probes.

We believe that a revisit of expression patterns in both B. floridae and B. lanceolatum and, essentially, in the Asian species Branchiostoma belcheri, will help to elucidate if the discrepancies reported come from truly species-specific differences or have an experimental nature.

\section{Escape from spatial and temporal colinearity}

In B. lanceolatum, Hox6 was expressed slightly more rostrally than Hox4 and thus did not maintain spatial colinearity. It was also expressed in an earlier stage (midneurula) than that of the onset of Hox4 expression (late neurula), therefore, Hox6 also deviated from temporal colinearity. The function of Hox6 in amphioxus is not known, but it is likely involved in the patterning and regionalization of the CNS in a very specific domain of the neural plate at a very specific time in development. In vertebrates, Hox6 is expressed in the spinal cord behind the rhombencephalon to the caudal end of the spinal cord and also in the mesoderm. Therefore, the expression of Hox6 of amphioxus and vertebrates is not conserved. Given that the vertebrate Hox6 genes maintain both spatial and temporal colinearity, we believe 
that they represent the ancestral condition, while the expression of amphioxus Hox6 is probably more divergent. In addition, we have shown that Hox6 is still regulated (directly or indirectly) by RA, as are the more anterior Hox genes [18], suggesting that it is derived from the ancestral state of canonical nested expression together with its mode of regulation.

The expression of amphioxus Hox6 and the effects of RA and the RA antagonist are very similar to those of the amphioxus ParaHox gene Gsx [45]. Amphioxus Gsx is expressed in a few cells in the neuroectoderm, at the level of somite 5, just anterior to the Hox6 domain. Amphioxus Hox6 and Gsx likely participate in the A-P patterning of limited parts of the neuroectoderm in a similar manner, probably in combination with other $H o x$ genes that overlap with them. RA treatments enlarge and shift the Gsx rostral limit of expression anteriorly whereas RA antagonist treatments make the Gsx domain disappear, as in the case of Hox6. As with the posterior limit of Hox6, which is unaffected by RA treatment, the posterior limit of Gsx did not change dramatically with RA treatment. Therefore, as Osborne et al. [45] have suggested for Gsx, the anterior limit of Hox6 would be regulated by RA, but the posterior limit would not. Thus, in both Hox6 and Gsx, the loss of the domain following BMS009 treatment can be explained by a caudal shift of the anterior limit until it reaches its posterior one, making the expression to disappear. In vertebrates, it is not known whether Hox6 paralogs are direct targets of RA regulation. However, other central Hox genes such as $H o x A 7$ and $H o x C 8$ shift their anterior limit rostrally in the paraxial mesoderm of mouse embryos after RA treatment (Hox-1.1 and Hox-3.1, respectively, in [10]), and different Hox4 paralogs have been shown to be regulated directly by RA [47-49]. However, in other cases such as in the chicken neural tube, the expression levels of genes from HoxB6 to HoxB9 have been shown to be refractory to RA treatment [50]. Thus, further investigation is needed in both cephalochordates and vertebrates to understand the ancestral mode of regulation of the central Hox genes by RA.

We have also detected the expression of three other Hox genes not studied so far: Hox7, Hox10, and Hox 14 . While the anterior limit of Hox7 expression is similar to that of Hox4 at the late neurula stage, it was more caudal from the pre-mouth larval stage onwards, thus keeping its spatial colinearity. However, the anterior limit of Hox10 expression in the CNS and mesoderm seemed to be more anterior than that of Hox4 and Hox7. Nonetheless, it is necessary to point out that the anterior limits of amphioxus Hox7 and Hox10 were very diffuse, unlike their vertebrate counterparts, which usually display sharp rostral limits, and their colinearity nature is then far from conclusive. Although this difference in the anterior limit between amphioxus and vertebrates might reflect different modes of regulation, we believe that this is the result of the clearly segmental nature of the vertebrate CNS (for example, rhombomeres) compared with the amphioxus CNS. Thus, the real anterior level up to where these genes are expressed in amphioxus might be different to that detected by WISH and thus their colinearity might differ, as discussed here. In vertebrates, Hox6 and Hox10 paralogs retain their colinearity and they have important opposite roles: Hox6 genes encode rib-promoting factors whereas Hox10 genes are ribinhibiting [51]. Thus, the colinear expression of Hox6 and Hox 10 genes in vertebrates is under strong developmental constraints that are not present in amphioxus, allowing these genes to escape from colinearity.

The most striking case of colinearity breakage is that of Hox 14. Posterior Hox genes are involved in the appearance of morphological innovations and are also related to changes in the evolution of the vertebrate bauplan, such as the type of vertebrae [52] or morphological variability within squamates [53]. Interestingly, lamprey and shark Hox14 genes have non-canonical expression patterns. They are expressed only in the posterior part of the endoderm in the lamprey and in a very specific posteroventral area in the shark surrounding the cloaca [35]. Amphioxus Hox14 is expressed in anterior structures such as the cerebral vesicle. This is the first Hox gene to be detected in such an important organ. In vertebrates, no $H o x$ genes are expressed in the midbrain or forebrain and all are excluded from Otx and Pax expression territories. However, what was thought to be a universal rule is broken in amphioxus. Likewise, the expression of Hox 14 in the pharyngeal endoderm is an exceptional case, because no amphioxus Hox gene has been detected earlier in the pharynx. RA regulates the expression of Hox14 in the notochord and mid-posterior gut in the same manner as anterior genes (enlarged expression anteriorly when embryos are treated with RA, or posterior shift of the anterior limit when treated with an RA antagonist; arrows in Figure 4B-B", C-C"). On the other hand, Hox 14 seems not to be regulated by RA in the pharynx, because RA treatment did not make the expression disappear, and nor did treatment with the antagonist expand it posteriorly (Figure 4B-B", C-C", black arrowheads) as would be expected. Surprisingly, Hox14 regulation in the cerebral vesicle appeared to be very sensitive to RA, because both excess and a drop in RA level affected its expression strongly (Figure 4B-B", C-C", white arrowheads). Thus, the regulatory regions of Hox14 must be modular. Some expression domains, namely the gut and the notochord, would depend upon RA. Although we cannot discern from the data presented here whether this control is direct or indirect, the presence of DR1 elements within amphioxus Hox14 
locus could give clues for future experiments. Thus, an RA-independent module might regulate the pharyngeal endoderm domain. By contrast, a module sensitive to RA concentration might control the cerebral vesicle domain, perhaps from an indirect effect of RA treatment on some transcription factors that are directly regulated by RA. For vertebrates, a putative regulation of Hox 14 by RA has not been studied. However, other posterior Hox genes respond in the opposite way to the anterior genes. For example, HoxB9 is refractory to RA treatment in the neural tube of chicken embryos, as is HoxB6 [50], and in the mouse a putative function of RA seems to be to prevent the expression of posterior HoxD genes in the anterior domain $[54,55]$.

The uncoupling of vertebrate and amphioxus Hox14 genes from a canonical Hox code is one sign of relaxation of the posterior part of the cluster, but not the only one. Posterior Hox genes of cephalochordates, urochordates, echinoderms, and hemichordates do not have clear orthologous relationships to the posterior paralogy groups of vertebrates [34], probably because of the higher evolutionary rate of this class of genes, a phenomenon named deuterostome posterior flexibility [56]. If the posterior Hox genes of amphioxus and vertebrates are true orthologs, our data imply that decoupling from the Hox code of Hox 14 genes occurred in the last common ancestor of chordates. However, although not conclusively, phylogenetic analyses of deuterostome posterior Hox genes, including the recently reported amphioxus Hox 15, suggest that the posterior Hox genes of amphioxus and vertebrates likely originated from independent duplications $[17,34,35]$. In line with the posterior flexibility hypothesis, the intergenic regions of the posterior Hox cluster are less conserved than the anterior ones in both amphioxus [37,38] and gnathostomes [57]. This trend for the posterior Hox cluster might be explained if the posterior genes had originated by specific expansions, for example, via tandem duplication, to give 14 Hox genes in the last common ancestor of vertebrates and 15 in Branchiostoma. Santini et al. [57] suggested that this lack of constraint among the posterior Hox cluster would have allowed these genes to be involved in the patterning of secondary axes in vertebrates, such as fins and limbs. In amphioxus, the same reasoning would apply to Hox 14 and its unusual expression territories. If the origin of the posterior Hox cluster is truly independent, the decoupling of the Hox14 genes from the classical Hox code must have happened independently in the amphioxus and vertebrate lineages.

\section{Conclusions}

The escape of Hox genes from canonically nested expression is not unusual. For instance, the Hox 1 and Hox 2 paralogs of vertebrates also do not follow spatial colinearity, so that the anterior limit of Hox 2 is more rostral than that of Hox 1 , which is expressed only in rhombomere 4. This delimited expression of $\operatorname{Hox} 1$ without extension to more caudal regions is similar to that of amphioxus Hox 1 in the CNS. However, it is worth noting that this similarity cannot account for any homology between the Hox 1 domain in amphioxus and rhombomere 4 in vertebrates. Furthermore, in lampreys, temporally colinear expression of Hox genes has not been detected [58]. Thus, different Hox genes, in different animals escape in one way or another from the colinearity 'rule'. We believe that these escapes might be associated with the patterning of lineage-specific morphological traits that first requires a loss of the constraint that kept them colinear.

\section{Additional files}

Additional file 1: Table S1. Sequences of primers used in this study to clone B. lanceolatum Hox gene probes.

Additional file 2: Figure S1. Expression of B. lanceolatum Hoxl at early neurula (A), mid neurula (B) and late neurula $(C)$ and Hox3 in the same stages $(D, E, F)$ in dorsal view. The arrows mark the expression in the epidermis, from mid-neurula in the case of Hoxl and late neurula in Hox3.

\section{Competing interests}

The authors declare that they have no competing interests.

\section{Authors' contributions}

JP-A carried out the WISH experiments in amphioxus and performed the genomic DNA analysis for RAREs. NA carried out cloning experiments. SA synthesized and provided the RA antagonist BMS009. SK discussed the results critically. JP-A, SDA, and JG-F conceived the study, participated in the design and coordination of the project, and wrote the draft manuscript. All authors read, discussed, and approved the manuscript.

\section{Acknowledgements}

We thank the anonymous reviewers for constructive criticisms that improved the manuscript. We are indebted to Hector Escriva and the ASSEMBLE FP7 EU programme for providing space and support during amphioxus sampling in Laboratoire Aragó, Banyuls-sur-mer, France. We thank Ina Arnone and Rossella Annunziata of the Stazione Zoologica Anton Dohrn of Naples (Italy) for their kind help in RA experiments and Ángel R. de Lera for providing the RA antagonist BMS009. We also thank Beatriz Albuixech-Crespo for her kind help with preparing the figures. The authors thank Senda Jiménez-Delgado, Ignacio Maeso, Manuel Irimia, Beatriz Albuixech-Crespo, and Ildikò M. L. Somorjai for their fruitful suggestions and discussions. We also want to thank Ignacio Maeso and Manuel Irimia for critical reading of the manuscript. This work was supported by the Ministerio de Educación y Ciencia (Spain) BMC2008-03776 and BFU2011-23921 and the ICREA prize to JGF. JP-A held a 'Fl' PhD fellowship of the Generalitat de Catalunya (Spain) and SDA a 'Juan de la Cierva' postdoctoral contract of the Ministerio de Educación y Ciencia (Spain).

\section{Author details}

'Departament de Genètica and Institut de Biomedicina (IBUB), University of Barcelona, Av. Diagonal, 643, Barcelona 08028, Spain. ²Laboratory for Evolutionary Morphology, RIKEN Center for Developmental Biology, 2-2-3 Minatojima-minamimachi, KobeHyogo 650-0047, Japan. ${ }^{3}$ Department of Organic Chemistry, Universidade de Vigo, Vigo, Pontevedra 36310, Spain. ${ }^{4}$ Cellular and Developmental Biology, Stazione Zoologica Anton Dohrn, Villa Comunale, Naples 80121, Italy.

Received: 25 June 2012 Accepted: 4 October 2012

Published: 3 December 2012 


\section{References}

1. Alexander T, Nolte C, Krumlauf R: Hox genes and segmentation of the hindbrain and axial skeleton. Annu Rev Cell Dev Biol 2009, 25:431-456.

2. McGinnis W, Krumlauf R: Homeobox genes and axial patterning. Cell 1992, 68:283-302.

3. Pearson JC, Lemons D, McGinnis W: Modulating Hox gene functions during animal body patterning. Nat Rev Genet 2005, 6:893-904.

4. Wellik DM: Hox genes and vertebrate axial pattern. Curr Top Dev Biol 2009, 88:257-278.

5. Kuraku S, Meyer A: The evolution and maintenance of Hox gene clusters in vertebrates and the teleost-specific genome duplication. Int J Dev Biol 2009, 53:765-773.

6. Lemons D, McGinnis W: Genomic evolution of Hox gene clusters. Science 2006, 313:1918-1922.

7. Duboule $D$, Dolle $P$ : The structural and functional organization of the murine HOX gene family resembles that of Drosophila homeotic genes. EMBO J 1989, 8:1497-1505.

8. Duboule D: Temporal colinearity and the phylotypic progression: a basis for the stability of a vertebrate Bauplan and the evolution of morphologies through heterochrony. Development Supp/ 1994, 135-142.

9. Izpisúa-Belmonte JC, Falkenstein H, Dollé P, Renucci A, Duboule D: Murine genes related to the Drosophila $A b d B$ homeotic genes are sequentially expressed during development of the posterior part of the body. EMBO J 1991, 10:2279-2289.

10. Kessel M, Gruss P: Homeotic transformations of murine vertebrae and concomitant alteration of Hox codes induced by retinoic acid. Cell 1991, 67:89-104.

11. Shimeld SM, Holland PWH: Vertebrate innovations. Proc Natl Acad Sci U S A 2000, 97:4449-4452.

12. Delsuc F, Brinkmann H, Chourrout D, Philippe H: Tunicates and not cephalochordates are the closest living relatives of vertebrates. Nature 2006, 439:965-968.

13. Ikuta T, Yoshida N, Satoh N, Saiga H: Ciona intestinalis Hox gene cluster: Its dispersed structure and residual colinear expression in development. Proc Natl Acad Sci U S A 2004, 101:15118-15123.

14. Spagnuolo A, Ristoratore F, Di Gregorio A, Aniello F, Branno M, Di Lauro R: Unusual number and genomic organization of Hox genes in the tunicate Ciona intestinalis. Gene 2003, 309:71-79.

15. Seo HC, Edvardsen RB, Maeland AD, Bjordal M, Jensen MF, Hansen A, Flaat M, Weissenbach J, Lehrach H, Wincker P, Reinhardt R, Chourrout D: Hox cluster disintegration with persistent anteroposterior order of expression in Oikopleura dioica. Nature 2004, 431:67-71.

16. Putnam NH, Butts T, Ferrier DE, Furlong RF, Hellsten U, Kawashima T, Robinson-Rechavi M, Shoguchi E, Terry A, Yu JK, Benito-Gutierrez EL, Dubchak I, Garcia-Fernandez J, Gibson-Brown JJ, Grigoriev IV, Horton AC, de Jong PJ, Jurka J, Kapitonov W, Kohara Y, Kuroki Y, Lindquist E, Lucas S, Osoegawa K, Pennacchio LA, Salamov AA, Satou Y, Sauka-Spengler T, Schmutz J, Shin-I T, et al: The amphioxus genome and the evolution of the chordate karyotype. Nature 2008, 453:1064-1071.

17. Holland LZ, Albalat R, Azumi K, Benito-Gutiérrez E, Blow MJ, Bronner-Fraser M, Brunet F, Butts T, Candiani S, Dishaw LJ, Ferrier DE, Garcia-Fernandez J, Gibson-Brown Jj, Gissi C, Godzik A, Hallbook F, Hirose D, Hosomichi K, Ikuta T, Inoko H, Kasahara M, Kasamatsu J, Kawashima T, Kimura A, Kobayashi M, Kozmik Z, Kubokawa K, Laudet V, Litman GW, McHardy AC, et al:

The amphioxus genome illuminates vertebrate origins and cephalochordate biology. Genome Res 2008, 18:1100-1111.

18. Schubert M, Holland ND, Laudet V, Holland LZ: A retinoic acid-Hox hierarchy controls both anterior/posterior patterning and neuronal specification in the developing central nervous system of the cephalochordate amphioxus. Dev Biol 2006, 296:190-202.

19. Schubert M, Holland ND, Escriva H, Holland LZ, Laudet V: Retinoic acid influences anteroposterior positioning of epidermal sensory neurons and their gene expression in a developing chordate (amphioxus). Proc Natl Acad Sci U S A 2004, 101:10320-10325.

20. Schubert M, Yu JK, Holland ND, Escriva H, Laudet V, Holland LZ: Retinoic acid signaling acts via Hox 1 to establish the posterior limit of the pharynx in the chordate amphioxus. Development 2005, 132:61-73.

21. Blumberg B, Bolado J Jr, Moreno TA, Kintner C, Evans RM, Papalopulu N: An essential role for retinoid signaling in anteroposterior neural patterning. Development 1997, 124:373-379.
22. Dupé $\mathrm{V}$, Lumsden $\mathrm{A}$ : Hindbrain patterning involves graded responses to retinoic acid signalling. Development 2001, 128:2199-2208.

23. Escriva H, Holland ND, Gronemeyer H, Laudet V, Holland LZ: The retinoic acid signaling pathway regulates anterior/posterior patterning in the nerve cord and pharynx of amphioxus, a chordate lacking neural crest. Development 2002, 129:2905-2916.

24. Holland LZ, Holland ND: Expression of AmphiHox-1 and AmphiPax-1 in amphioxus embryos treated with retinoic acid: insights into evolution and patterning of the chordate nerve cord and pharynx. Development 1996, 122:1829-1838.

25. Bastien J, Rochette-Egly C: Nuclear retinoid receptors and the transcription of retinoid-target genes. Gene 2004, 328:1-16.

26. Balmer JE, Blomhoff R: Gene expression regulation by retinoic acid. J Lipid Res 2002, 43:1773-1808.

27. Marlétaz F, Holland LZ, Laudet V, Schubert M: Retinoic acid signaling and the evolution of chordates. Int J Biol Sci 2006, 2:38-47.

28. Dupé V, Davenne M, Brocard J, Dollé P, Mark M, Dierich A, Chambon P, Rijli FM: In vivo functional analysis of the Hoxa-13' retinoic acid response element (3'RARE). Development 1997, 124:399-410.

29. Huang D, Chen SW, Gudas LJ: Analysis of two distinct retinoic acid response elements in the homeobox gene Hoxb1 in transgenic mice. Dev Dyn 2002, 223:353-370.

30. Langston AW, Thompson JR, Gudas LJ: Retinoic acid-responsive enhancers located 3' of the Hox A and Hox B homeobox gene clusters. Functional analysis. J Biol Chem 1997, 272:2167-2175.

31. Manzanares M, Wada H, Itasaki N, Trainor PA, Krumlauf R, Holland PW: Conservation and elaboration of Hox gene regulation during evolution of the vertebrate head. Nature 2000, 408:854-857.

32. Wada $H$, Escriva $H$, Zhang $S$, Laudet V: Conserved RARE localization in amphioxus Hox clusters and implications for Hox code evolution in the vertebrate neural crest. Dev Dyn 2006, 235:1522-1531.

33. Cohn MJ: Evolutionary biology: lamprey Hox genes and the origin of jaws. Nature 2002, 416:386-387.

34. Feiner N, Ericsson R, Meyer A, Kuraku S: Revisiting the origin of the vertebrate Hox 14 by including its relict sarcopterygian members. J Exp Zool B Mol Dev Evol 2011, 316:515-525.

35. Kuraku S, Takio Y, Tamura K, Aono H, Meyer A, Kuratani S: Noncanonical role of Hox14 revealed by its expression patterns in lamprey and shark. Proc Natl Acad Sci U S A 2008, 105:6679-6683.

36. Fuentes M, Benito E, Bertrand S, Paris M, Mignardot A, Godoy L, Jiménez-Delgado S, Oliveri D, Candiani S, Hirsinger E, D'Aniello $S$, Pascual-Anaya J, Maeso I, Pestarino M, Vernier P, Nicolas JF, Schubert M, Laudet V, Geneviere AM, Albalat R, Garcia-Fernandez J, Holland ND, Escriva $\mathrm{H}$ : Insights into spawning behavior and development of the European amphioxus (Branchiostoma lanceolatum). J Exp Zool B Mol Dev Evol 2007, 308:484-493.

37. Pascual-Anaya J, D'Aniello $S$, Garcia-Fernàndez J: Unexpectedly large number of conserved noncoding regions within the ancestral chordate Hox cluster. Dev Genes Evol 2008, 218:591-597.

38. Amemiya CT, Prohaska SJ, Hill-Force A, Cook A, Wasserscheid J, Ferrier DE, Pascual-Anaya J, Garcia-Fernàndez J, Dewar K, Stadler PF: The amphioxus Hox cluster: characterization, comparative genomics, and evolution. J Exp Zool B Mol Dev Evol 2008, 310:465-477.

39. Oulion S, Bertrand S, Belgacem MR, Le Petillon Y, Escriva H: Sequencing and analysis of the Mediterranean amphioxus (Branchiostoma lanceolatum) transcriptome. PLoS One 2012, 7:e36554.

40. Irimia M, Piñeiro C, Maeso I, Gómez-Skarmeta JL, Casares F, Garcia-Fernàndez J: Conserved developmental expression of Fezf in chordates and Drosophila and the origin of the Zona Limitans Intrathalamica (ZLI) brain organizer. Evo Devo 2010, 1:7.

41. Sandelin A, Wasserman WW: Prediction of nuclear hormone receptor response elements. Mol Endocrinol 2005, 19:595-606.

42. Wada H, Garcia-Fernàndez J, Holland PW: Colinear and segmental expression of amphioxus Hox genes. Dev Biol 1999, 213:131-141.

43. Somorjai IML, Bertrand S, Camasses A, Haguenauer A, Escriva H: Evidence for stasis and not genetic piracy in developmental expression patterns of Branchiostoma lanceolatum and Branchiostoma floridae, two amphioxus species that have evolved independently over the course of 200 Myr. Dev Genes Evol 2008, 218:703-713.

44. Koop D, Holland ND, Sémon M, Alvarez S, de Lera AR, Laudet V, Holland LZ, Schubert M: Retinoic acid signaling targets Hox genes 
during the amphioxus gastrula stage: insights into early anteriorposterior patterning of the chordate body plan. Dev Biol 2010, 338:98-106.

45. Osborne PW, Benoit G, Laudet V, Schubert M, Ferrier DE: Differential regulation of ParaHox genes by retinoic acid in the invertebrate chordate amphioxus (Branchiostoma floridae). Dev Biol 2009, 327:252-262.

46. Holland ND: Early central nervous system evolution: an era of skin brains? Nat. Rev Neurosci 2003, 4:617-627.

47. Gould A, Itasaki N, Krumlauf R: Initiation of rhombomeric Hoxb4 expression requires induction by somites and a retinoid pathway. Neuron 1998, 21:39-51.

48. Packer Al, Crotty DA, Elwell VA, Wolgemuth DJ: Expression of the murine Hoxa4 gene requires both autoregulation and a conserved retinoic acid response element. Development 1998, 125:1991-1998.

49. Zhang F, Nagy Kovács E, Featherstone MS: Murine hoxd4 expression in the CNS requires multiple elements including a retinoic acid response element. Mech Dev 2000, 96:79-89.

50. Bel-Vialar S, Itasaki N, Krumlauf R: Initiating Hox gene expression: in the early chick neural tube differential sensitivity to FGF and RA signaling subdivides the HoxB genes in two distinct groups. Development 2002, 129:5103-5115.

51. Mallo M, Wellik DM, Deschamps J: Hox genes and regional patterning of the vertebrate body plan. Dev Biol 2010, 344:7-15.

52. Burke AC, Nelson CE, Morgan BA, Tabin C: Hox genes and the evolution of vertebrate axial morphology. Development 1995, 121:333-346.

53. Di-Poï N, Montoya-Burgos JI, Miller H, Pourquié O, Milinkovitch MC, Duboule D: Changes in Hox genes' structure and function during the evolution of the squamate body plan. Nature 2010, 464:99-103.

54. Niederreither K, Vermot J, Schuhbaur B, Chambon P, Dollé P: Embryonic retinoic acid synthesis is required for forelimb growth and anteroposterior patterning in the mouse. Development 2002, 129:3563-3574.

55. Yashiro K, Zhao X, Uehara M, Yamashita K, Nishijima M, Nishino J, Saijoh Y, Sakai Y, Hamada H: Regulation of retinoic acid distribution is required for proximodistal patterning and outgrowth of the developing mouse limb. Dev Cell 2004, 6:411-422

56. Ferrier DEK, Minguillón C, Holland PW, Garcia-Fernàndez J: The amphioxus Hox cluster: deuterostome posterior flexibility and Hox14. Evol Dev 2000, 2:284-293.

57. Santini S, Boore JL, Meyer A: Evolutionary conservation of regulatory elements in vertebrate Hoxgene clusters. Genome Res 2003, 13:1111-1122.

58. Takio Y, Kuraku S, Murakami Y, Pasqualetti M, Rijli FM, Narita Y, Kuratani S, Kusakabe R: Hox gene expression patterns in Lethenteron japonicum embryos-insights into the evolution of the vertebrate Hox code. Dev Biol 2007, 308:606-620

doi:10.1186/2041-9139-3-28

Cite this article as: Pascual-Anaya et al:: Broken colinearity of the amphioxus Hox cluster. EvoDevo 2012 3:28.

\section{Submit your next manuscript to BioMed Central and take full advantage of:}

- Convenient online submission

- Thorough peer review

- No space constraints or color figure charges

- Immediate publication on acceptance

- Inclusion in PubMed, CAS, Scopus and Google Scholar

- Research which is freely available for redistribution

Submit your manuscript at www.biomedcentral.com/submit
Ciomed Central 